\title{
COMPOSTOS COM
}

\section{SÍNDROME E COMPLEXO \\ NO PORTUGUÊS BRASILEIRO:}

\author{
UMA ABORDAGEM \\ CONSTRUCIONAL ${ }^{1}$
}

\section{COMPUESTOS CON SÍNDROME Y COMPLEXO EN PORTUGUÉS BRASILEÑO: UN ENFOQUE CONSTRUCCIONAL}

\author{
COMPOUNDS WITH SÍNDROME AND COMPLEXO IN BRAZILIAN PORTUGUESE: A \\ CONSTRUCTIONAL APPROACH
}

Natival Almeida Simões Neto*

Universidade Estadual de Feira de Santana

Universidade Federal da Bahia

\begin{abstract}
RESUMO: Neste trabalho, serão estudados os compostos instanciados pelos esquemas [Síndrome [X]]N e [Complexo [SP]]N, com base nos pressupostos teóricos da Morfologia Construcional (BOOIJ, 2010; GONÇALVES, 2016). Os dados foram coletados em publicações de sites brasileiros, no século XXI. Alguns exemplos encontrados são síndrome de Peterpan, complexo de Wendy, complexo de vira-lata, complexo de Cinderela e síndrome de Dona Florinda. Este estudo ainda visa contribuir com as discussões acerca da herança semântica em relação aos compostos. Para isso, foi revisitada a pouca literatura sobre o assunto, o que inclui Corbin (1990), Booij (2017) e Soledade (2018a), tendo esses autores atentado mais contundentemente para aspectos da derivação sufixal. PALAVRAS-CHAVE: Composição. Morfologia construcional. Polissemia. Herança.
\end{abstract}

\footnotetext{
${ }^{1}$ Trabalho apresentado como comunicação oral no VI Congresso Internacional sobre a Metáfora na Linguagem e no Pensamento, que aconteceu entre os dias 24 e 27 de outubro de 2017, na Universidade Federal da Bahia.

* Professor Substituto da Universidade Estadual de Feira de Santana. Doutorando em Linguística Histórica no Programa de Pós-Graduação em Língua e Cultura, da Universidade Federal da Bahia, onde fez graduação e mestrado. É bolsista da Fundação de Amparo à Pesquisa do EstadodaBahia. E-mail: <nativalneto@gmail.com>.
} 
RESUMEN: En este trabajo, se estudiarán los compuestos instanciados por los esquemas [Síndrome [X]]N y [Complexo [SP]]N, con base en los presupuestos teóricos de la Morfología Construccional (BOOIJ, 2010; GONÇALVES, 2016). Los datos fueron recolectados en publicaciones de sitios brasileños, en el siglo XXI. Algunos ejemplos encontrados son síndrome de Peterpan, complexo de Wendy, complexo de vira-lata, complexo de Cinderela y síndrome de Dona Florinda. Este estudio también pretende contribuir con las discusiones acerca de la herencia semántica en relación a los compuestos. Para eso, se revisó la poca literatura sobre el asunto, lo que incluye Corbin (1990), Booij (2017) y Soledade (2018a), estando estos autores más contundentemente atentos a los aspectos de la derivación de sufijos.

PALABRAS CLAVE: Composición. Morfología construccional. Polisemia. Herencia.

ABSTRACT: In this paper, the compounds instantiated by the schemes [Síndrome $[\mathrm{X}]]_{\mathrm{N}}$ and $[\text { Complex }[\mathrm{SP}]]_{\mathrm{N}}$, based on the theoretical assumptions of Constructional Morphology (BOOIJ, 2010; GONÇALVES, 2016) will be studied. The data were collected from publications of Brazilian websites, in the $21^{\text {st }}$ century. Some examples are sindrome de Peterpan, complexo de Wendy, complexo de vira-lata, complexo de Cinderela, and síndrome de Dona Florinda. This study also aims to contribute to discussions about the semantic inheritance in relation to the compounds. For this, some literature on the subject were reviewed, including Corbin (1990), Booij (2017), and Soledade (2018a), having these authors tried most strikingly for aspects of the suffix derivation.

KEYWORDS: Composition. Construction Morphology. Polysemy. Heritage.

\section{CONSIDERAÇÕES INICIAIS}

Este trabalho pretende analisar formas compostas, encabeçadas pelos substantivos síndrome e complexo, tais como síndrome de Estocolmo, complexo de vira-lata, complexo de Cinderela, síndrome de Dona Florinda. Algumas dessas construções são comuns no jargão da Psicologia, onde se atestam a Síndrome de Peterpan e o Complexo de Electra. Ainda que usuais em contexto mais técnico, muitas dessas formas emergem do uso cotidiano, sem qualquer compromisso teórico, apenas baseando-se em compreensões ligeiras do que seja uma síndrome ou um complexo.

No Dicionário Houaiss eletrônico de Língua Portuguesa, de Houaiss e Villar (2009), entre as várias acepções dos verbetes síndrome e complexo, aparecem as seguintes:

Rubrica: medicina.

Síndrome: conjunto de sinais e sintomas observáveis em vários processos patológicos diferentes e sem causa específica.

Rubrica: psicologia.

Complexo: sistema de ideias associadas (parcial ou totalmente inconscientes, vinculadas ao terreno da afetividade, contraditórias, não necessariamente reprimidas) capaz de levar o indivíduo a pensar, a sentir e por vezes a agir de acordo com um padrão de natureza definida.

São essas noções selecionadas que parecem entrar em jogo na formação dos compostos aqui analisados. É preciso destacar que, embora diferentes em suas especificidades, o falante comum não parece fazer distinções claras entre o que seja uma coisa ou outra. Isso que pode ser observado na recorrente variação, como acontece nos exemplos de (01) a (04):

(01) Quem é portador da síndrome de vira-lata não sabe valorizar o que é brasileiro, sempre despreza, ao passo que aceita e idolatra qualquer porcaria digna do monturo, basta ser americano ou europeu. Isso de fato tem que ser entendido como algum tipo de distúrbio (MIRANDA, 2017).

(02) Tem uma expressão brasileira, frequentemente mencionada, que parece resumir essa questão: complexo de vira-lata. A frase tem origem na derrota desastrosa do Brasil nas mãos da seleção uruguaia no Maracanã, na final da Copa de 1950. Foi usada 
por Nelson Rodrigues para descrever "a inferioridade em que o brasileiro se coloca, voluntariamente, em face do resto do mundo" (SMITH, 2015).

(03) O reaça rico a gente até entende. Compreensível ele ser conservador, defendendo a manutenção do status quo, sua posição e privilégios nesta sociedade tão hierarquizada como a brasileira. Agora, o Reaça Pobre é de f... Vive esmagado, frustrado, explorado, sob risco permanente, mas ainda diz sentir medo do "inimigo vermelho". Até hoje acredita em bicho papão. Precisa convencer a si mesmo que é um cara muito importante e diferente da "gentalha". Padece da síndrome de Dona Florinda (CASTILHO, 2014).

(04) No Brasil, há muita gente com uma forma de pensar muito semelhante, o que eu comecei a chamar de Complexo de Dona Florinda. Trata-se de pessoas de origem pobre e que ainda vivem em certo grau de pobreza, mas que abominam as pessoas ao seu redor, se entendem como diferentes, se acham mais inteligentes, mais estudadas, (quase nunca são realmente mais estudadas, mesmo assim se julgam mais instruídas), superiores, com uma compreensão mais clara do mundo (SIQUEIRA, 2014).

Para além do registro dessas formas duplas, este trabalho pretende interpretar essas construções, assumindo prerrogativas teóricas da Morfologia Construcional (MC) e da Linguística Cognitiva (LC). É preciso destacar que, em muitos dos dados recolhidos, a interpretação reivindica o conhecimento sociocultural prévio, para que se possa entender a funcionalidade do composto. Por exemplo, para se compreender a Síndrome ou Complexo de Dona Florinda, é preciso que a pessoa minimamente reconheça a referência da personagem do seriado Chaves. Por isso, optou-se por modelos de análise que evitam polarizar o conhecimento linguístico e o conhecimento enciclopédico.

Feitas essas considerações iniciais, o artigo se estrutura da seguinte maneira: na seção 2, serão apresentados alguns pressupostos teóricos da MC, como proposta por Booij $(2010,2017)$ e Gonçalves e Almeida (2016). Será dada maior atenção aos aspectos relacionados à composição. Na seção 3, dividida em três subseções, discutem-se questões ligadas à herança semântica da base, a partir das formulações de Corbin (1990) e Booij (2017) e Soledade (2018a). Na seção 4, são apresentadas a análise dos dados e a discussão dos resultados. Essa seção está dividida em duas subseções: a primeira faz uma análise sobre a polissemia das construções, seguindo a MC; ao passo que a segunda analisa a questão da herança semântica nos compostos. Na seção 5, são feitas as considerações finais.

\section{MORFOLOGIA CONSTRUCIONAL: PRESSUPOSTOS TEÓRICOS E ABORDAGENS DA COMPOSIÇÃO}

O modelo da MC começa a ser desenvolvido pelo linguista holandês Geert Booij, em 2005, com o texto "Compounding and derivation: evidence for Construction Morphology" (BOOIJ, 2005) e tem seu ápice em 2010, com a publicação do livro "Construction Morphology" (BOOIJ, 2010). Esse estudioso começou a sua trajetória nos estudos morfológicos no âmbito do gerativismo lexicalista associativo. Na década de 1980, com o texto "Form and meaning in morphology: the case of Dutch 'agent' nouns", Booij (1986) se aproximava de outros morfólogos gerativistas de todo o mundo, como Jackendoff (1975), Basílio (1980), Bauer (1983) e Corbin (1990), na busca de um modelo associativo em que a parte formal não se sobrepusesse à parte semântica nas análises.

A MC é um desdobramento da Gramática de Construções, como proposta por Goldberg $(1995,2006)$ que, por sua vez, se insere no paradigma teórico da LC. No livro Construction Morphology, Booij (2010) defende que "[...] uma abordagem construcional possibilita tratar mais satisfatoriamente a relação entre semântica, sintaxe, morfologia e léxico, observando melhor as semelhanças de formação nos níveis da palavra e da frase" (GONÇALVES; ALMEIDA, 2016, p. 23). O esquema morfológico, principal recurso de análise na MC, consegue captar essa relação, agrupando características formais, funcionais e semânticas das construções.

Importa destacar que, diferentemente das regras de formação de palavras gerativistas (ARONOFF, 1976), que se centraram fortemente na investigação da derivação, os esquemas morfológicos de Booij (2010) abarcam sufixal-derivados (arrochadeira, palmiteiro, paneleiro), prefixal-derivados (cisgênero, cissexual, cisnormatividade), compostos sintagmáticos (mulher da vida, morador de rua, garoto de programa), compostos morfológicos ${ }^{2}$ (afródromo, manifestódromo, fumódromo), recomposições

${ }^{2}$ Esse termo é utilizado por Villalva (2003). 
(homocomportamento, homofobia, homoescândalo), splinters (umburoska, cajaroska, cajuroska) e expressões semiabertas (pé de manga, pé de caju, pé de feijão). Essa diversidade de aplicações pode ser observada no livro de Gonçalves (2016).

A visão de léxico explorada na MC pode ser representada como na Figura 1, extraída do trabalho de João Tavares da Silva (2017).

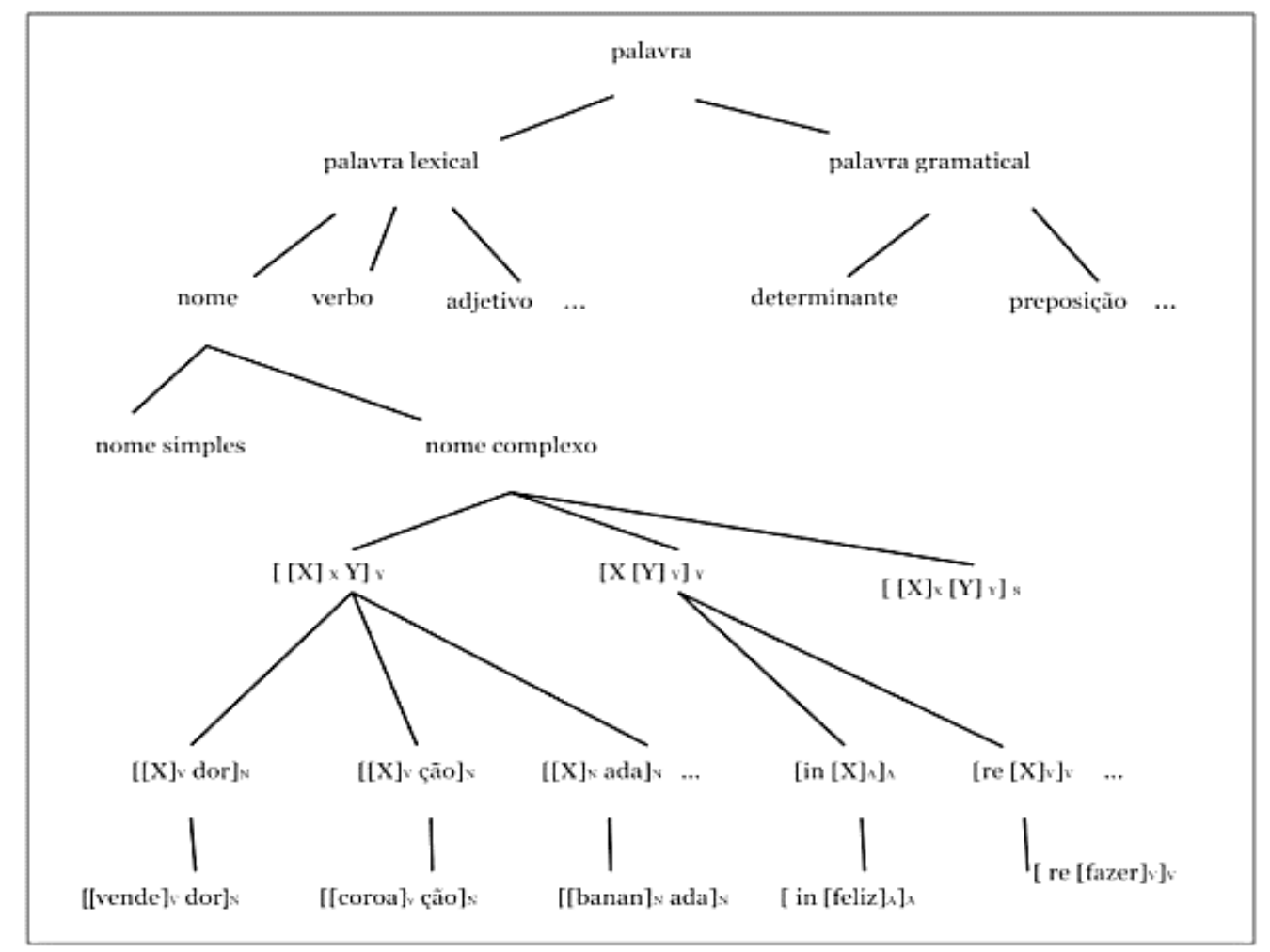

Figura 1: Representação do léxico hierárquico da Morfologia Construcional

Fonte: Silva, J. (2017, p. 38)

Abaixo do nó 'nome complexo', na Figura 1, estão as representações de esquemas de sufixação, prefixação e composição, respectivamente. Note-se que as configurações esquemáticas dos processos são bastante similares e respeitam os mesmos princípios. Independente do nível de estruturação, no âmbito da MC, ser uma palavra complexa e motivada por um esquema significa herdar deste algumas informações substanciais, tais como forma fonológica, categoria lexical ou sintático-funcional e propriedade semântica.

Suponha-se que um falante seja exposto a palavras como tatuador, maquiador, cobrador, vendedor e entregador. Após essa exposição, será criado, em sua mente, um esquema com as seguintes informações: (i) forma fonológica recorrente - dor; (ii) categoria lexical recorrente substantivo; e (iii) significado recorrente de agente profissional. Isso permitirá que ele tanto possa formar novas palavras com esse esquema, como interpretar aquelas que ele nunca ouviu. Em termos teóricos, chegar-se-ia a uma formulação como $\left[[\mathrm{X}]_{\mathrm{V}} \mathrm{dor}\right]_{\mathrm{N}} \leftrightarrow$ agente profissional envolvido em significado de $\left.\mathrm{X}_{V}\right]$. Mas esse mesmo falante pode se deparar, posteriormente, com construções como apagador, cortador, aparador, gravador, computador, provador, corredor, seguidor gozador, e ser capaz de elaborar outros esquemas com outros significados que se relacionam, de alguma maneira, com aquele de agente profissional. É possível chegar, então, a uma representação como a da Figura 2, extraída de Simões Neto (2017). 


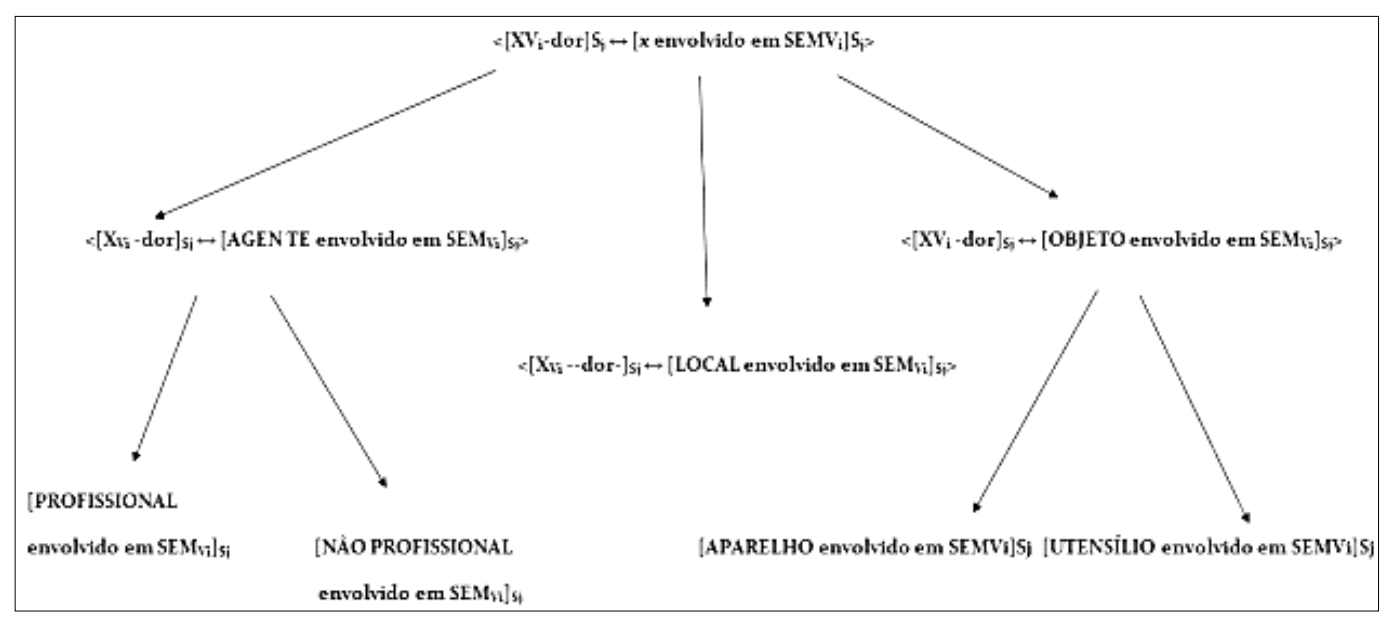

Figura 2: Representação da polissemia das construções X-dor

Fonte: Simões Neto (2017, p. 470)

Na Figura 2, a representação esquemática das construções substantivas $X_{V}$-dor começa inicialmente com um esquema genérico que trata de sinalizar que os significados dos três esquemas dominantes (AGENTE, LOCAL, OBJETO) estão interligados de alguma maneira. Esses esquemas dominantes podem ainda se especializar semanticamente e reivindicarem subesquemas, como PROFISSIONAL e NÃO PROFISSIONAL, para o esquema AGENTE, e APARELHO e UTENSÍLIO, para o esquema OBJETO. À medida que uma diferença semântica se tornar produtiva, esta pode e deve ser representada em esquemas.

Mesmo a Figura 2 representando um esquema de sufixação, nos esquemas de composição pode haver uma polissemia que merece ser representada. Booij (2017), por exemplo, observa que se pode depreender um esquema formativo como o substantivo holandês hoofd (cabeça) em núcleo de compostos, quando passa a ter o significado de principal, casos de hoofd-bezwaar (objeção principal), hoofd-doel (objetivo principal), hoofd-gedachte (ideia principal) e hoofd-ingang (entrada principal). A partir dessas realizações, podese chegar a um esquema " $<\left[[\text { hoofd }]_{\mathrm{Ni}} \mathrm{N}_{\mathrm{j}}\right]_{\mathrm{Nk}} \leftrightarrow\left[\text { SEM }_{\mathrm{j}} \text { PRINCIPAL }_{\mathrm{i}}\right]_{\mathrm{k}}$ ”".

No Brasil, raros são os estudos que se voltam para a composição morfossintática em perspectiva construcional. Muito tem sido feito no que toca às fronteiras entre composição e derivação, com base nos compostos morfológicos, como X-teca (MELO, 2017). O trabalho que ora se apresenta, portanto, é um dos poucos que investem nesse tipo de formação. Pesquisas como a de Neide Higino da Silva (2011), com expressões a partir de pé, e a de Faria (2011), com compostos a partir de bolsa, embora lancem mão da LC nas análises, não trabalham com a MC.

\section{A HERANÇA SEMÂNTICA DA BASE NOS ESTUDOS MORFOLÓGICOS}

Nesta seção, será feito um apanhado das abordagens do fenômeno de herança semântica da base. Sobre isso, foram encontrados três trabalhos: (i) Corbin (1990), dentro de uma proposta gerativista lexicalista associativa, que trabalha com regras de formação de palavras, significados construídos pela regra e significados herdados da base; (ii) Booij (2017), em um modelo construcional que trabalha com as noções de herança padrão e múltipla herança; (iii) Soledade (2018a), em uma abordagem também construcional, porém estabelecendo associações com outras teorias da Linguística Cognitiva.

Tanto o modelo gerativista lexicalista, a partir de Jackendoff (1975), quanto o construcional apostam, em tese, em uma morfologia baseada em palavras, ou seja, as análises partem da ideia de que palavras formam palavras. No entanto, uma característica que diferencia, de maneira fundante, essas abordagens é que o lexicalismo é um modelo orientado para as bases (inputs) e, sobre elas, incidem as regras de formação, ao passo que o construcionismo é orientado para os produtos (outputs). Isso fica claro no fato de o lexicalismo investir, de maneira rígida, nas hipóteses de Aronoff (1976) da 'base palavra', da 'base única' e do 'produto categorial único', enquanto o construcionismo, de Booij (2010), só conserva a última hipótese, acreditando que as características da base 
podem ser omitidas em algumas descrições, mas não as do produto. Essa diferença terá um impacto nas abordagens da herança semântica da base, como se poderá ver nas subseções a seguir.

\subsection{A PROPOSTA DE CORBIN (1990) EM UM MODELO LEXICALISTA ASSOCIATIVO}

Em Associativité et stratification dans la représentation des mots construits, Danielle Corbin (1990), mesmo dentro de um paradigma gerativista, ressalta a importância de se investigar a interpretação semântica das palavras construídas ${ }^{3}$. Corbin (1990, p. 44) distingue dois tipos de significado, que podem, às vezes, coincidir: o significado atestado (SA) e o significado previsível (SP). O SA é o significado de uma palavra tal como se atesta nos dicionários de língua contemporânea, e o SP é o significado formulado a partir da operação semântica que diz respeito à regra que constrói a palavra, podendo ser, portanto, uma hipótese do linguista com base na teoria utilizada para a descrição do componente derivacional.

O SP, segundo Corbin (1990), apresenta duas subespecificações: o significado previsível construído para a regra (SPCR) e o significado previsível herdado da base (SPHB). O SPCR é o significado comum a todas as palavras derivadas de uma mesma regra de construção, sem levar em conta a natureza das bases nem os procedimentos morfológicos envolvidos. O SPHB, por sua vez, é o significado comum a todos os produtos de uma regra de construção de palavras construídas sobre bases do mesmo tipo semântico, representando, portanto, uma especificação do SPCR diante das condições semânticas da base.

Para melhor explicar a sua proposta, Corbin (1990, p. 45) utiliza o adjetivo coquelucheux, reproduzido em (05) ${ }^{4}$. A proposta foi aplicada para o português, com o adjetivo canceroso $^{5} \mathrm{em}(06)$ :

SPCR: << en relation avec la coqueluche $>>$

ex: une toux coquelucheuse $=$ une toux de coqueluche

le bacille coquelucheux = le bacille de la coqueluche

$\mathrm{SA}:<<$ de la coqueluche $>>$

SPHB: $<<$ atteint de coqueluche $>>$

ex: un enfant coquelucheux = un enfant atteint de coqueluche

$\mathrm{SA}:<<$ atteint de coqueluche $>>$

(06) SPCR: << que tem câncer $>>$

ex: um tumor canceroso = um tumor que tem câncer

uma célula cancerosa = uma célula que tem câncer

$\mathrm{SA}:<<$ relativo ao ou próprio do câncer $>>$

SPHB: $<<$ que sofre de câncer $>>$

ex: $u m$ homem canceroso $=$ um homem que sofre de câncer

SA: $<<$ que ou aquele que apresenta câncer $>>$

\footnotetext{
${ }^{3}$ Cabe aqui mencionar que o termo 'palavra construída', usado por Corbin (1990), não se relaciona com a Morfologia Construcional, de Booij (2010). Corbin está inserida em um paradigma gerativista lexicalista, enquanto Booij está em um paradigma cognitivista.

${ }^{4}$ Aqui, apresentamos uma tradução livre para o exemplo em (05), extraído de Corbin (1990). Esclarecemos, de imediato, que não há uma correspondência para o adjetivo coquelucheux no português. Utilizamos, portanto, a forma coqueluchoso.

SPCR: <<relacionado à coqueluche $>>$

Ex: uma tosse "coqueluchosa" = uma tosse da coqueluche

O bacilo "coqueluchoso" = o bacilo da coqueluche

SA: $<<$ da coqueluche $>>$

SPHB: $<<$ que sofre de coqueluche $>>$

Ex: uma criança "coqueluchosa" = uma criança que sofre de coqueluche

SA: <<afetada pela coqueluche >>

${ }^{5}$ O dicionário de referência para esse exemplo foi o de Houaiss e Villar (2009).
} 
No exemplo em (05), em francês, o SPCR se baseia no significado relacional dos adjetivos derivados em -eux, o que pode ser observado também em scrupuleux. Esse primeiro SA se aproxima, então, do SPCR. O SPHB se aproxima do segundo SA, apresentando o sentido de alguém que sofre do mal expresso pela base. Esse significado pode ser observado também em cancéreux (canceroso), alguém que sofre de câncer. É nesse contexto que surge a noção de herança para Corbin (1990): o significado de alguém que sofre de só aparece em bases que designam doenças ou males, como coqueluche e câncer. Assim, um significado recorrente em construções com -eux é mediado por um tipo semântico específico da base. Com o adjetivo courageux (corajoso), a base courage (coragem) não licencia o mesmo SPHB que se vê em cancéreux e coquelucheux, pois não é do mesmo tipo semântico.

O exemplo em (06), em português, ratifica a proposta de Corbin (1990). O SPCR apresenta a noção de posse intensiva ou provimento, que caracteriza as palavras construídas em -oso, como pode ser observado em seboso (que tem muito sebo) e vaidoso (que tem muita vaidade). O primeiro SA, apesar de passível de aproximação, não é igual ao SPCR. Sobre o SPHB, a ideia de que sofre de somente é licenciada para bases que designam doença, como se pode ver em leproso (aquele que sofre de lepra) e não se pode admitir com oleoso ( ${ }^{*}$ aquele que sofre de óleo). É o mesmo que acontece com os casos em -eux do francês : de uma base de grupo semântico específico, herda-se uma interpretação semântica que passa a ser recorrente às palavras construídas por uma dada regra.

A noção de herança semântica da base, de acordo com Corbin (1990), está, então, relacionada à capacidade de o significado proveniente da palavra base orientar para um significado específico dentro das possibilidades do significado previsto para a regra pela qual a palavra se construiu. Outros exemplos podem ser vistos com as palavras construídas com o sufixo português -ense, formador de adjetivos relacionais. Sejam tomadas as formações ${ }^{6}$ circense, canadense e florense, respectivamente, em (07), (08) e (09):
SPCR: $<<$ relativo ou referente ao circo $>>$
$\mathrm{SA}:<<$ relativo ou pertencente a circo $>>$
ex: práticas circenses $=$ práticas relacionadas ao circo
SPHB: $<<$ que trabalha no circo $>>$
ex: artista circense $=$ artista que trabalha no circo

SPCR: << relativo ou referente ao Canadá>>

SA: <<relativo ao Canadá ou o que é seu natural ou habitante $>>$

ex: políticas canadenses $=$ políticas do Canadá

SPHB: <<que é nascido no Canadá>>

ex: cantora canadense = cantora nascida no Canadá

(09) SPCR: $<<$ relativo ou referente a Joaquim de Flora $^{7}>>$

SA: $<<$ relativo à ordem monástica católica fundada por Joaquim de Flora $>>$

ex: congregação florense ${ }^{8}$ : congregação referente à ordem fundada por Joaquim de Flora.

SPHB: <<aqueles que são sectários da ordem fundada por Joaquim de Flora >>;

ex: abade florense ${ }^{9}$

Os exemplos (07), (08) e (09) compartilham o mesmo SPCR, pois são três palavras construídas com o sufixo -ense, que, segundo Cunha (2007), apresenta o valor de relação, procedência ou origem. Por outro lado, as bases a que os sufixos se aplicam são de tipos semânticos distintos, logo os SPHBs apresentam diferenças. O significado que parece ser mais recorrente com as palavras

\footnotetext{
${ }^{6}$ Os significados atestados foram extraídos de Houaiss e Villar (2009).

${ }^{7}$ Joaquim de Flora foi um abade e filósofo italiano. Não raramente, encontra-se a grafia original Joaquim de Fiore.

${ }^{8}$ Dado visto no trabalho Considerações sobre o pensamento trinitário de Joaquim de Fiore em suas relações com as filosofias especulativas da história, de Dobroruka (2000, p. 12).

${ }^{9}$ Dado visto no trabalho Ação, escolha e justiça: Joaquim de Fiore e a inversão de Trasímaco, de Rossatto, Costa e Ter Regeen (2006, p. 4).
} 
construídas com esse sufixo é o SPHB em (08), com o valor de gentílico. Não são raras formações como feirense, fluminense, catarinense, parisiense etc. Essa interpretação semântica, no entanto, só é possível porque as bases das formações apresentam um tipo semântico determinado: são nomes de lugares plenamente especificados pelo nome próprio. Por isso, é possível atribuir a noção de proveniência. Assim, herda-se, de um grupo de bases, um significado específico dentro de um quadro mais geral.

Nota-se, também, que as formações em (07) e (08) não herdam o mesmo tipo de interpretação que (09). Em (07), a base apresenta um valor locativo de pouca especificidade, o que não viabiliza o significado de proveniência, mas licencia o significado de agentivo profissional (que trabalha no circo), se assemelhando ao adjetivo forense (advogado forense). Por último, (09) tem como base um nome próprio com valor não locativo; logo, não é possível o significado de proveniência. A interpretação semântica de agentividade é licenciada para esse caso, mas de forma diferenciada da que se vê em (07), pois a base parece restringir essa leitura. Assim, herdase o significado de agente sectário ou habitual, em que a base Joaquim de Flora é tomada pela sua obra, o que configura uma relação metonímica do tipo criador/criatura ou autor/obra.

O trabalho de Corbin (1990), embora inovador, por descrever questões de interpretação semântica na construção de palavras, principalmente na relação entre base, palavra derivada e significado da palavra derivada, ainda precisa explicar, com maiores detalhes, como essas unidades se relacionam. Isso seria considerar como os mecanismos de polissemia, decorrentes de fenômenos de metonímia e metáfora, se mostram importantes para a compreensão dos significados herdados. Porém, essa possibilidade parece distante dentro de um modelo gerativista. Somente em um modelo onde questões dessa natureza sejam, de fato, primordiais, isso será mais bem explicado.

\subsection{A PROPOSTA DE BOOIJ (2017) EM UM MODELO CONSTRUCIONAL}

No texto Inheritance and motivation in Construction Morphology, Booij (2017) discute a noção de herança no âmbito da MC, destacando dois tipos de herança: a herança padrão e a múltipla herança. $\mathrm{O}$ autor começa a sua explanação com o agente nominal eater, do inglês, derivado sufixalmente do verbo eat. O esquema de formação de palavras que descreve a formação desse nome pode ser representado como: "< $<[\mathrm{x}]_{\mathrm{V}}$ er $]_{\mathrm{Nj}} \leftrightarrow\left[\text { Agente de } \mathrm{SEM}_{\mathrm{i}}\right]_{\mathrm{j}}$ ".

Esse esquema morfológico especifica a relação sistemática entre nomes da forma [V-er] e o significado 'Agente da ação expressa pela base verbal'. A construção eater é uma instanciação desse esquema, a partir da compatibilização desse esquema com o input to eat. No entendimento do autor, o léxico é parcialmente concebido como uma rede hierárquica na qual nós inferiores (ou os nós mais baixos), as palavras complexas existentes, podem assumidamente herdar informação dos nós mais altos dominantes. Então, há uma relação vertical entre o esquema de formação de palavras e as palavras complexas motivadas por ele. Booij (2017) ainda destaca que o significado da palavra formada (output) está também relacionado, de alguma maneira, ao da palavra base. O significado de eater, portanto, reflete parcialmente o significado de to eat.

Isso significa que, na $\mathrm{MC}$, a herança não é somente uma relação entre o esquema e o output, mas também entre esse e o seu input. Para Booij (2017), o primeiro tipo de relação é a de instanciação, enquanto o segundo caracteriza uma relação de subparte. Assim, o significado da palavra complexa pode ser herdado de mais de uma fonte, isto é, há múltipla herança. Em se tratando de composição, uma palavra composta será ligada a um esquema de composto e às subpartes dos compostos que, geralmente, formam entradas lexicais independentes. Exemplo do autor é o composto pasta eater, cujo significado pode ser compreendido tanto pela forma e pelo significado especificados no esquema de formação de palavras para compostos NN quanto pelos significados dos nomes pasta e eater.

Um exemplo para análise da importância semântica do input é dado por Booij (2017), com a variação nas categorias lexicais das bases em nomes diminutivos do holandês. Embora esses diminutivos sejam derivados de nomes, eles também derivam ocasionalmente de palavras base de outras categorias, como mostrado em (10). 
$(10)$

\begin{tabular}{c|c|c} 
Categoria & Base & Diminutivo \\
\hline $\mathrm{N}$ & vrouw 'woman' (mulher) & vrouw-tje 'little woman, sweetheart' (mulher pequena) \\
\hline A & lief'sweet' (doce) & lief-je 'sweetheart' (namorada) \\
\hline V & dut 'to nap'(cochilar) & dut-je 'nap'(cochilo) \\
\hline Adv & tien 'ten'(dez) & tien-tje '10 guilder note' (cédula de 10) \\
\hline NP & uit 'out' (fora) & uit-je 'outing' (passeio) \\
\hline PP & twaalf uur'12 o'clock' (12 horas) & twaalfuur-tje 'packed lunch' (marmita) \\
\hline Pronome & dit en dat 'this and that' (Isto e aquilo) & onderons-je 'private chat' (chat privado)
\end{tabular}

Quadro 1: Diminutivos em holandês

Fonte: Booij (2017,p. 14, tradução nossa para o português)

Esses dados mostram que as oscilações na categoria lexical da base prototípica $[\mathrm{N}]$ existem. Esses desvios são característicos de uma muito produtiva categoria que pode expandir seu domínio de aplicação ocasionalmente para palavras base de outras categorias ${ }^{10}$. Assim, nós podemos considerar esses nomes diminutivos como sendo motivados por um esquema " $<\left[[\mathrm{X}]_{\mathrm{Ni}}(\mathrm{t})_{\mathrm{j}} \mathrm{e}\right]_{\mathrm{Nj}} \leftrightarrow[\mathrm{PEQUENO}$ $\left.\mathrm{SEM}_{\mathrm{i}}\right]_{\mathrm{j}}>”$

Porém, é preciso destacar que, a depender da informação semântica do input, o significado do produto pode ir além do que é previsto no esquema. É aí que entra a questão da herança semântica da base. Bases cujas categorias lexicais sejam, por exemplo, numerais (tien), advérbios (uit) e sintagmas nominais (twaalf uur), ao aparecerem em construções com o formativo holandês de diminutivo (t)je, orientam as palavras complexas para outro significado que não de tamanho pequeno. Isso é dizer que o input restringe de alguma forma o significado dos outputs, devendo, portanto, haver compatibilização entre esquema, input output.

Outro exemplo dado por Booij (2017) é com o formativo holandês-achtig, que toma nomes, verbos e adjetivos como input, como se pode ver em (11).

(11)

\begin{tabular}{c|c|c}
\hline Categoria & Palavra-base & Adjetivo derivado \\
\hline & rots 'rock' (rocha) & rots-achtig 'rocky' (rochoso) \\
\hline $\mathrm{N}$ & & \\
\hline & weiger 'to refuse' (recusar) & weiger-achtig 'refusing persistently' (recusa persistente) \\
\hline $\mathrm{V}$ & \multicolumn{2}{|}{} \\
\hline & & \\
\hline & & \\
\hline $\mathrm{A}$ & groen 'green' (verde) & groen-achtig 'greenish' (esverdeado) \\
\hline
\end{tabular}

Quadro 2: Construções X-achtig do holandês

Fonte: Booij (2017, p. 16, tradução nossa para o português)

\footnotetext{
${ }^{10}$ Isso acontece os sufixo de grau -inho do português. Para maiores detalhes, ver Gonçalves (2013).
} 
Booij (2017), a respeito dessas construções X-achtig, observa ainda que, quando combinadas com um input da categoria lexical nome, as palavras complexas podem apresentar três significados sistemáticos: como $N$, possui $N$, e ligado a $N$. O detalhamento do autor (BOOIJ, 2017, p. 16) está em (12), com traduções nossas entre parênteses.

soldaat-achtig 'soldier-like' (como um soldado)

rots-achtig 'rock-possessing, rockys' (possui rocha; rochoso)

pasta-achtig 'pasta-liking, pasta-minded (ligado aos Correios)

Com base nesses exemplos, Booij (2017) se pergunta se o processo de formação de palavras com o sufixo -achtig poderia ser caracterizado como restrito a bases $[\mathrm{N}]$ com ocasional substituição dessa restrição por adjetivos. O autor diz que não, porque se perderia a generalização de que a ligação de - achtig a verbos e adjetivos é produtiva e sistemática também. Além disso, observa-se que há também uma correlação sistemática entre a categoria da palavra base e a contribuição para o significado da construção.

Nos casos das construções em (12), pode-se prever um significado geral de 'relativo a’ para os três exemplos. Porém, o tipo de relação que se estabelece muda conforme a informação semântica encontrada no input. À medida que essas diferenças se tornarem produtivas, esses deslocamentos semânticos devem ser representados na relação entre esquema e subesquema.

Embora Booij (2017) reconheça a importância da herança semântica da base nas palavras complexas, essa informação não tem sido captada de maneira satisfatória nas representações dos esquemas morfológicos. Além disso, não há explicação como essa herança da base pode se dar: metáfora, metonímia ou ajuste focal.

\subsection{AS OBSERVAÇÕES E CONTRIBUIÇÕES DE SOLEDADE (2018) PARA AS ABORDAGENS SOBRE A HERANÇA}

Nos textos "De pecadores a sabedores: agentes de -dor no Livro das Aves" e "Por uma abordagem cognitiva da morfologia: revisando a Morfologia Construcional”, Soledade (2018a, 2018b) retoma as discussões de Corbin (1990) e Booij (2017) acerca da herança semântica da base. A autora procura, inicialmente, estabelecer um diálogo entre as propostas, utilizando as noções de esquema da MC e dando destaque substancial à participação da base na geração da polissemia, como se viu na proposta gerativista.

Soledade (2018a) faz suas observações, a partir das construções $\mathrm{X}_{\mathrm{S}}$-udo em português, abordando-as, inicialmente, sob a proposta de Corbin (1990). Sobre as construções $\mathrm{X}_{\mathrm{S}}$-udo, a autora entende que o sentido previsível construído pela regra é representável pela paráfrase "[...] provido de característica física relativa a [sentido da base] ressaltada”, como se pode ver em barbudo, bundudo, narigudo e cabeludo. No entanto, quando a regra se aplica a certos tipos de substantivos, taxados de defectivos/irregulares por Corbin (1990), pode-se encontrar formas como abelhudo, carrancudo, pontudo, taludo, troncudo e varudo. Como observa Soledade (2018a), nesses casos, as bases não licenciam o significado da regra anteriormente mencionada. Em termos construcionais, seria dizer que não há compatibilização entre input e esquema, demandando, provavelmente, uma especificação. A autora segue a sua formulação com os exemplos cabeçudo (13), sisudo (14) e façanhudo (15), cujas acepções (significados atestados) foram colhidas no Aulete dicionário online.

\section{CABEÇUDO}

1. Diz-se de pessoa que tem a cabeça grande;

2. Diz-se daquilo que tem a parte superior ou a extremidade dilatadas ou arredondadas;

3. Fig. Teimoso, perseverante s.m.;

4. Indivíduo cabeçudo, que tem cabeça grande.

\section{(14) SISUDO}

1. Que tem muito siso, prudência; CIRCUNSPECTO;

2. Que se irrita facilmente, que costuma ficar de cenho franzido, de cara fechada; 
3. Pessoa ajuizada, responsável, prudente.

\section{FAÇANHUDO}

1. Que pratica muitas façanhas;

2. P.ext. Que provoca desordem (brutamontes façanhudo); VALENTÃO;

3. Fig. Mal-encarado, facínora.

A análise de Soledade (2018a) sobre esses três construtos se dá da seguinte maneira: em cabeçudo, a palavra cabeça é o input e, por ser uma parte do corpo, é adequada ao significado do primeiro grupo, que inclui cabeludo e narigudo. Isso é visível no fato de esse significado "pessoa que tem a cabeça grande" encabeçar o significado atestado. No entanto, vê-se também o significado de "teimoso, perseverante', que está relacionado a fatores socioculturais e linguísticos que orientam para um significado não previsível nem pela base, nem pela regra. Porém, é a base cabeça, tomada como a 'sede da razão, da ideia e do raciocínio', que se pode tomar a pessoa teimosa como 'aquela que persevera em um raciocínio, que tem ideia fixa em algo’.

Quanto a sisudo e façanhudo, Soledade (2018a) destaca o distanciamento semântico em relação às outras bases que, geralmente, aparecem nas construções $\mathrm{X}_{\mathrm{S}}$-udo. Explica a autora que,

[n]o primeiro caso, sendo a base a palavra SISO ‘juízo’ uma faculdade humana, o indivíduo pode ser provido ou desprovido dele, em demasia ou em parcimônia, sendo o SP ainda elencado como o primeiro no SA. Havendo ainda a extensão de sentido metafórica 'carrancudo, cara-fechada', donde podemos relacionar ao ditado popular "muito riso, pouco siso". Já em FAÇANHUDO, o sentido previsível não vem listado dentre os SA, e associação a esse não se dá tão diretamente, pois sendo FAÇANHA algo que se pratica e não algo que se possui, é pouco clara a associação entre a palavra construída e o sentido a ser especificado pela regra/esquema. Para além disso, FAÇANHUDO também sofre extensão metafórica, que cresce no sentido pejorativo FAÇANHUDO 'que pratica muitas façanhas' > 'que provoca desordem (com suas façanhas)/ desordeiro, valentão' > 'mal-encarado, facínora' (SOLEDADE, 2018a, p. 7).

Ao se voltar para o modelo de Booij, Soledade (2018a) observa que não há como tratar da informação semântica da base nas representações esquemáticas da MC.

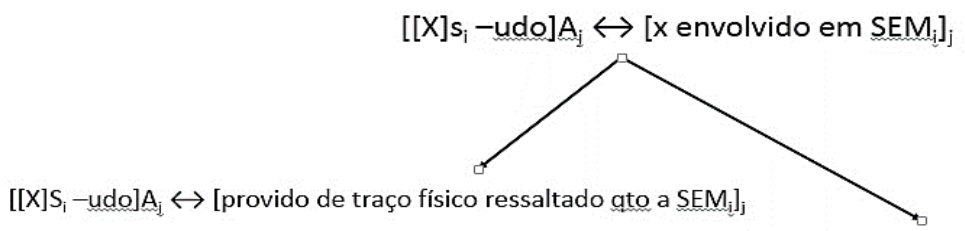

$\left[[X] \mathrm{S}_{\mathrm{i}}-\mathrm{udo}\right] \mathrm{A}_{\mathrm{j}} \leftrightarrow$ [provido de característica semelhante a $\left.\mathrm{SEM}_{\mathrm{i}}\right]_{\mathrm{j}}$

Figura 3: Representação da polissemia das construções X-udo

Fonte: Soledade (2018a, p.7)

A respeito da impossibilidade de os esquemas booijianos retratarem os fenômenos ligados à herança semântica da base, a autora comenta que,

[d]e fato, nesse tipo de formulação esquemática, não há como tratar da natureza semântica da base, ou seja, a herança da base não se enquadra na especificação dos subesquemas formulados, no entanto, como vimos, essa polissemia é parcialmente motivada pela herança da base, o que nos deixa o questionamento acerca de como adequar o modelo para dar conta desse aspecto. A nosso ver, essa é uma tarefa muito complicada se quisermos manter o modelo de representação booijiano, uma vez que a inclusão de especificações semânticas quanto às 
bases determinaria que os esquemas assumiriam uma extensão que impossibilitaria as representações lineares e verticais de subesquemas polissêmicos (SOLEDADE, 2018b, p. 250).

No que toca às análises de Soledade (2018a, 2018b), duas merecem ser destacadas, pois realçam a sua visão acerca da herança, que se diferencia tanto de Corbin (1990) quanto de Booij (2017). A primeira, já mencionada, é de cabeçudo, que tanto pode significar 'pessoa que tem a cabeça grande' como 'pessoa teimosa'. Isso está relacionado à polissemia que a própria base cabeça apresenta: “João está com um machucado na cabeça" e "João perdeu a cabeça".

Esse contraste semântico do input cabeça é percebido na formação derivada cabeçudo. Simões Neto (2016), trabalhando com as construções X-eiro do português arcaico, observou que a palavra cabeceira podia significar 'parte da cama onde se repousa a cabeça' ou 'chefe'. Essa polissemia também está relacionada à do input cabeça, que pode significar 'líder' ou realçar 'a parte superior de um objeto'.

Os exemplos mostram que a polissemia na MC devem ser analisadas para além das relações esquemas-subesquemas, devendo-se levar em consideração as polissemias das palavras individualmente e as dos inputs, de forma que essas possam apontar questões sobre a maneira como o significado opera na mente humana.

A segunda análise de Soledade (2018a) a ser destacada é a de fornigador (variante medieval de fornicador encontrada no Livro das Aves). Na sua explicação sobre essa construção, a autora comenta que

\footnotetext{
Essa instanciação parece ter se dado no latim, uma vez que encontramos registros da forma fornicator, -oris em dicionários da língua latina, em que a compatibilização do esquema se dá com o verbo intransitivo fornicare ter coito, prostituir-se'.

Sobre esse exemplo, chama à atenção a relação semântica do verbo com o substantivo que lhe deu origem. Segundo historiadores e etimólogos, o verbo fornicare teria sido formado no século III d.C, com base no nome fornix, icis 'abóbada, arco'. Assim, a relação de sentido entre a base nominal e o verbo será enviesada por um aspecto cultural relevante, uma vez que as prostitutas romanas costumavam se posicionar para fora das casas, sob os arcos ou abóbadas dessas entradas, assim uma referência a um local relacionado à prática da prostituição dará base para a formação de um verbo designador da ação. Não é incomum que lexias relacionadas a locais sejam tomadas metaforicamente e sirvam de base para instanciações diversas, observe-se o caso de praceiro 'sociável, agradável', tendo sido tomado o locativo praça como espaço de socialização sendo, portanto, 'aquele que frequenta a praça' uma pessoa 'sociável' > praceiro (SOLEDADE, 2018a, p. 14-15, grifos da autora).
}

Com esse segundo exemplo, Soledade (2018a) mostra a possibilidade de a polissemia, a metáfora, a metonímia atuarem significativamente no que se convencionou como sendo a herança semântica da base, de forma que: (i) a polissemia no input pode orientar para a polissemia no output, caso das formações a partir de cabeça; (ii) a base pode ser tomada metaforicamente, caso de cabeçudo com o significado de teimoso; e (iii) a base pode ser tomada metonimicamente, caso de fornix em fornigador. Essas considerações de Soledade, enfim, caracterizam uma terceira maneira de interpretar o fenômeno da herança semântica da base.

\section{DUAS ANÁLISES PARA AS CONSTRUÇÕES [SÍNDROME $[\mathrm{X}]]_{\mathrm{N}}$ E [COMPLEXO $\left.[\mathrm{SP}]\right]_{\mathrm{N}}$}

Nesta seção, serão apresentadas as análises feitas acerca dos compostos encabeçados por síndrome e complexo. Essas análises são divididas em duas partes: na primeira, será analisada a polissemia na perspectiva da MC; enquanto, na segunda, a análise se dará em torno das ideias de herança semântica do elemento não núcleo nos compostos.

Os dados coletados abordam 230 realizações de compostos com síndrome e trinta realizações a partir de complexo. Em se tratando de quantidade, já se pode supor que o primeiro é mais produtivo. Procurou-se aqui recolher, nos sites da internet, não só os 
compostos criativos e corriqueiros, como complexo de Dona Florinda e síndrome de underground, mas também aqueles já cristalizados e especializados, sobretudo em alguns jargões, como são os casos de Síndrome de Estocolmo e Complexo de Édipo.

\subsection{PRIMEIRA ANÁLISE: A POLISSEMIA CONSTRUCIONAL}

\subsubsection{Os compostos sindrome}

Em relação às construções com sindrome, a primeira coisa que se nota é que a parte variável apresenta diferentes configurações, como se pode ver no Quadro 3.

\begin{tabular}{c|c}
$\begin{array}{c}\text { Categoria } \\
\text { da parte variável }\end{array}$ & Exemplos \\
\hline Adjetivo & $\begin{array}{r}\text { síndrome anticolinérgica, síndrome compartimental, síndrome } \\
\text { floral, síndrome hepatorrenal. }\end{array}$ \\
\hline Siglas & $\begin{array}{r}\text { síndrome SAPHO, síndrome HELLP, síndrome CREST, síndrome } \\
\text { DRESS. }\end{array}$ \\
\hline Sintagma Preposicionado & $\begin{array}{r}\text { síndrome do pânico, síndrome de Oslo, síndrome de Peterpan, } \\
\text { síndrome do sotaque estrangeiro. }\end{array}$
\end{tabular}

Quadro 3: Categoria das partes variáveis nos compostos com síndrome

Fonte: Produzido pelo autor

Todos os exemplos no Quadro 3 estão relacionados a condições clínicas anômalas, reconhecidas por profissionais das áreas de Medicina e Psicologia. Estes foram 176 casos dos 230 totais. Os outros 54 exemplos se inserem no que aqui se chamou de compostos criativos que, embora apontem para algum comportamento anômalo, não têm um reconhecimento técnico. São os casos dos exemplos de (16) a (20).

(16) Tem gente que vem de rabo abanando quando termina o namoro, diz que agora já era, aí ataca a síndrome de trouxa volta com o/a ex. (CONSELHO DE NOIA, 2017)

(17) Meu pai tô com síndrome de virginiano só reglama [sic] de limpeza. (JAN, 2017)

(18) Eu me engano mt com as pessoas, tenho a síndrome da bela e a fera, fico tentando achar qualidades em quem na vdd é só um monstro msm (MARINATO, 2017).

PTB aparelhou a Casa da Moeda, agora está com síndrome de Tio Patinhas, não quer a privatização! (FERNANDES, 2017).

Síndrome de Luciano Huck. Gabeira apaga fotos com os amigos do MBL (DIÁRIO DO CENTRO MUNDO, 2017).

A fim de dar conta da polissemia tanto dos compostos do Quadro 3 quanto dos exemplos de (16) a (20), propõe-se, na Figura 4, uma representação esquemática: 


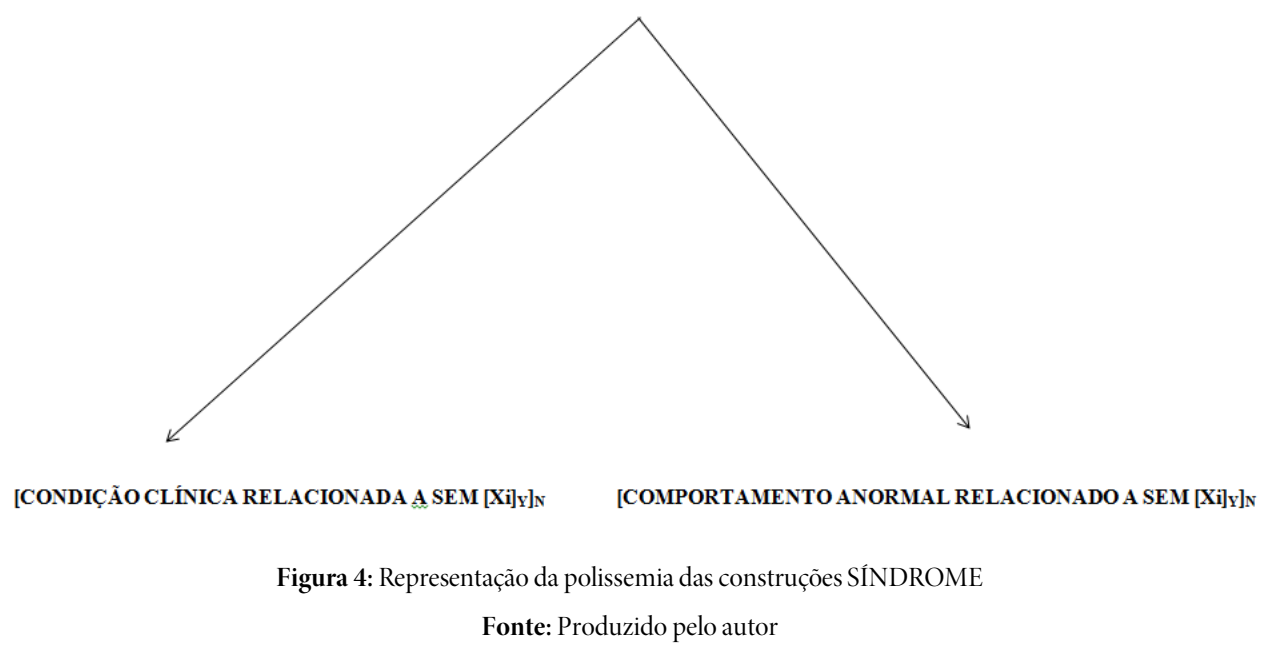

A Figura 4, ainda que explique a polissemia construcional do esquema [síndrome $[\mathrm{X}]]_{\mathrm{N}}$, não dá conta de explicar o fato de um comportamento anômalo não tratado clinicamente passar a ser abordado como uma condição clínica. Isso aconteceu com a chamada Síndrome de Peterpan: um comportamento generalizado, marcado por atitudes imaturas do ponto de vista psicológico, sexual e social, passou a ser abordado em estudos da Psicologia e Psicanálise e foi nomeada por Kiley (1983) de "Peter Pan Syndrome" (Síndrome de Peter Pan).

Outros exemplos que seguiram essa mesma tendência foram a Síndrome do impostor e a Síndrome do sotaque estrangeiro. Há outros casos, em que se mantém uma diferença entre uma designação popular do comportamento e o termo técnico da sindrome. Como exemplo, tem-se o nome popular Síndrome das lágrimas de crocodilo, em oposição ao nome técnico Síndrome de Bogorad. Isso é dizer que, do ponto de vista conceptual, o comportamento anômalo passou a ser abordado como uma condição clínica, mas, do ponto de vista linguístico, foi necessária uma adequação.

Com o intuito de sumarizar o fluxo entre o significado de "comportamento anormal", popularmente caracterizado, e o de "condição clínica”, propõe-se a representação da Figura 5, em que se admite a possibilidade de um significado passar a outro, destacando sempre o movimento que vai do mais geral para o mais específico.

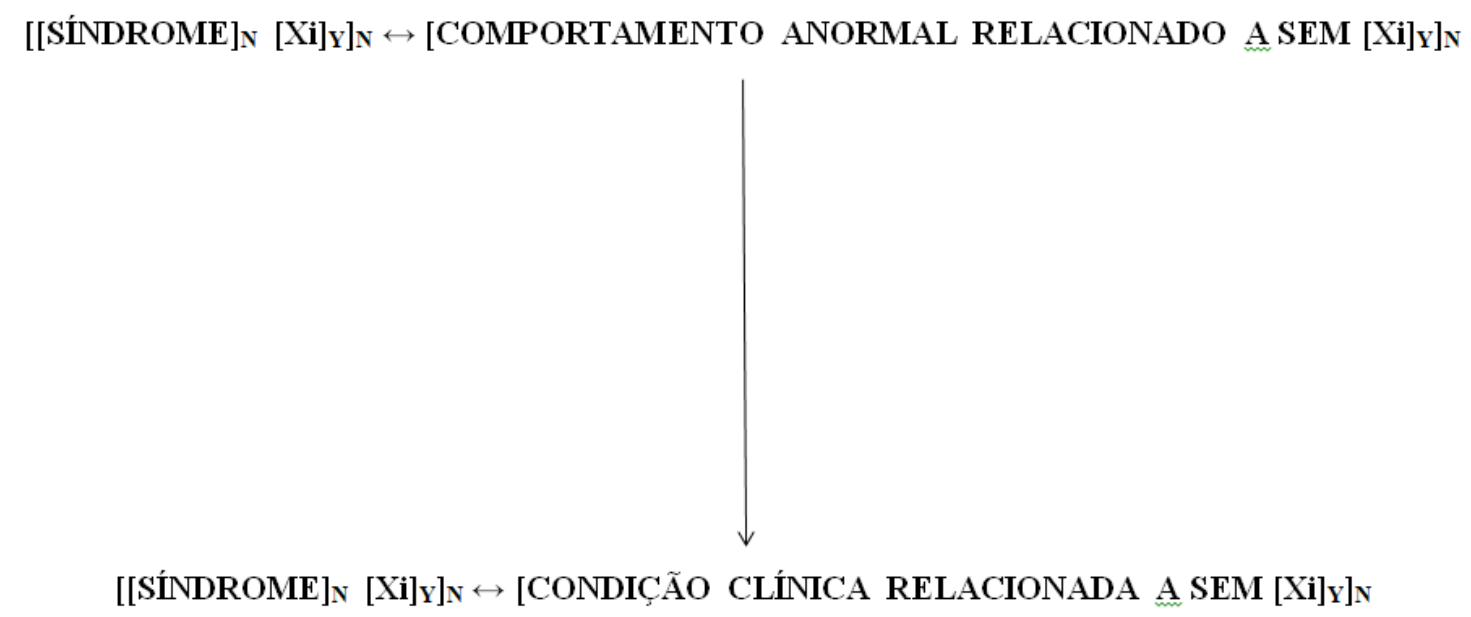

Figura 5: Extensão de significados entre os subesquemas das construções SÍNDROME

Fonte:Produzido pelo autor

4.1.2 Os compostos complexo 
Em relação às construções com complexo, observa-se que, dos trinta exemplos coletados, apenas em um, a parte variável não é um sintagma preposicionado. Foi o caso de complexo paterno. Constatada essa improdutividade de formas não preposicionadas na parte variável do composto, não há necessidade de deixar sem especificação essa categoria.

No que toca à semântica, verificam-se três significados diferentes: (i) noção coletiva que aparece comumente em topônimos que designam espaços habitacionais, como Complexo do Alemão, Complexo de Bangu, Complexo do Lins etc.; (ii) estado psicológico normalmente notificado no âmbito da Psicanálise, como Complexo de Édipo, Complexo de Electra, Complexo de Madonnaprostituta ${ }^{11}$, Complexo de Jocasta, complexo de inferioridade, complexo de superioridade, complexo de Messias etc.; (iii) comportamento anormal, como Complexo de Deus, complexo de adolescente, complexo do pau pequeno, complexo de manter o alto astral, complexo de magreza, complexo de bailarino. A Figura 6 representa, nos termos da MC, essa polissemia.

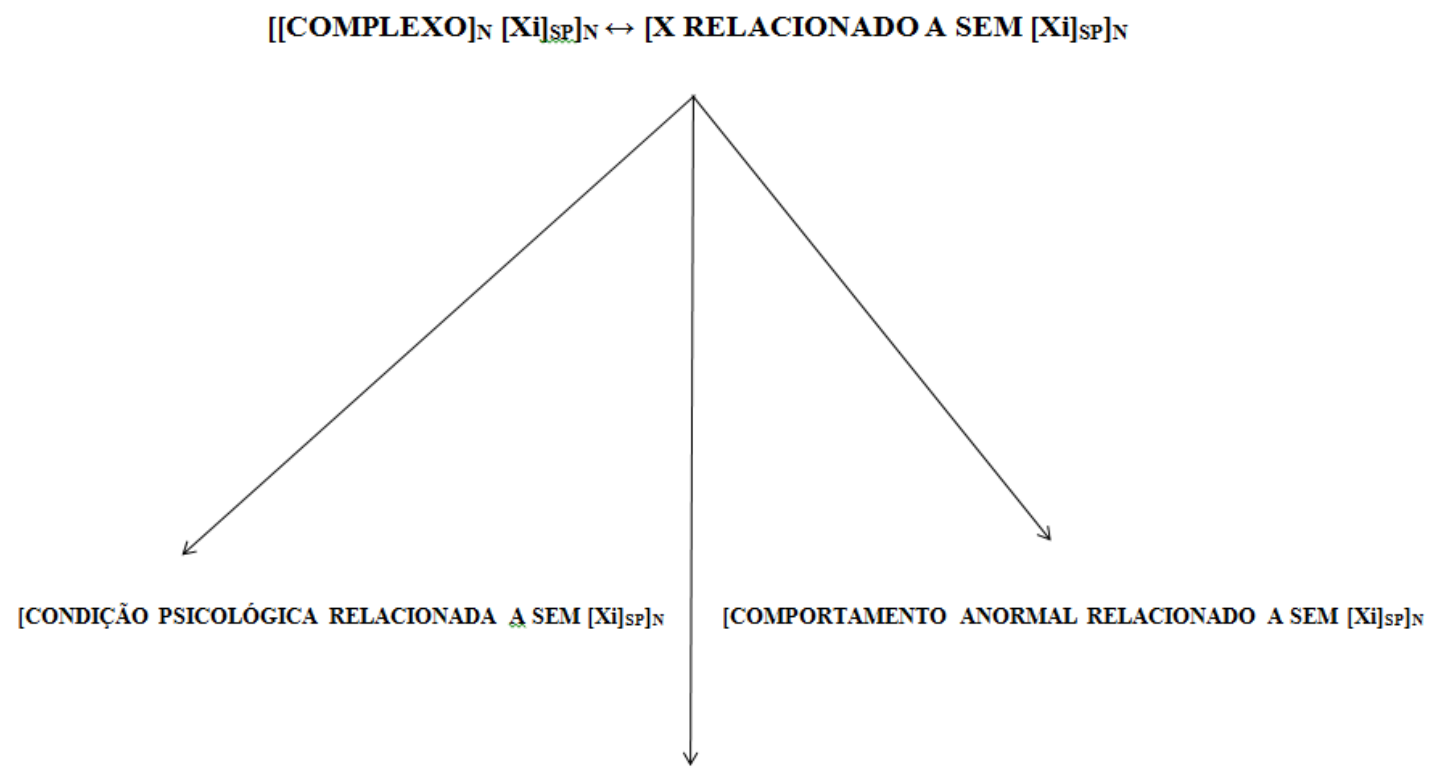

[NOÇÃo COLETIVA RELACIONADA A SEM [Xi]sp]N

Figura 6: Representação da polissemia das construções COMPLEXO

Fonte: Produzido pelo autor

Como se pode ver na Figura 6, o esquema dominante apresenta um caráter genérico, diferente do que aconteceu nas construções com síndrome. Isso se deu pelo fato de o significado de noção coletiva parecer mais distante dos outros dois. No entanto, é possível pensar minimamente na possibilidade de as formas instanciadas por esse esquema se relacionarem a espaços habitacionais muito populosos, o que pode sugerir alguma anomalia, ficando, assim, próximo dos outros significados.

Cabe destacar a presença do significado comportamento anormal, tanto nas construções com complexo quanto nas construções com síndrome. É justamente na relação com esse significado que aparecem as formas duplas, como as apresentadas nos exemplos de (01) a (04), complexo/síndrome de vira-lata, complexo/síndrome de Dona Florinda. Somam-se a esses, as realizações nos exemplos de (21) a (24), com complexo/síndrome de Peterpan e complexo/síndrome de Deus, respectivamente.

(21) Exato! Renato sabia das coisas, não tinha complexo de Peter Pan nem queria ser forever Young (MBRANDREA, 2017).

(22) “Ariana com síndrome do Peter Pan" PQP eu tô rindo muito (SAH, 2017).

\footnotetext{
${ }^{11}$ Esse complexofoi abordado por Sigmund Freud, sendo conceituada como uma impotência psíquica em que homens têm dificuldade em se relacionar sexualmente com mulheres, por enxerga-las ou como santas ou como prostitutas.
} 
Já repararam como eu me odeio e tenho complexo de Deus? É muito engraçado e explicável cientificamente (KINGCOCK, 2017).

(24) Quem Sérgio Moro pensa que é pra não cumprir a ordem do TRF4 de soltar Lula? Essa síndrome de Deus dele já foi longe demais (BARROS, 2018).

\subsection{SEGUNDA ANÁLISE: A HERANÇA SEMÂNTICA DO ELEMENTO NÃO NÚCLEO}

As discussões em torno da herança aqui apontadas se voltaram para a sufixação. Nesse tipo de derivação, prototipicamente, o sufixo é responsável pela informação do núcleo lexical da formação. Isso quer dizer que, quando as formas leiteiro, açougueiro e doceira são parafraseadas em $<$ A PESSOA QUE VENDE LEITE $>$, $<$ A PESSOA QUE TRABALHA NO AÇOUGUE $>\mathrm{e}<$ A PESSOA QUE FAZ DOCES>, a informação nuclear de "A PESSOA QUE" está relacionada ao sufixo - eir-. As bases, nesses casos leite, açougue e doce, acrescentam, via de regra, uma informação acessória e especificativa. Quando se fala em herança semântica da base, quer se destacar o papel que a base imprime no significado da palavra formada. No caso de açougueiro, por exemplo, a base açougue não é compatível com o significado de AQUELE QUE VENDE ou AQUELE QUE FAZ.

Com os compostos, não é muito diferente. Há, quase sempre, um elemento núcleo e outro não núcleo. Quando se observam os compostos dor de barriga, dor de cabeça, dor de facão, dor de cotovelo, o substantivo dor funciona como elemento núcleo, enquanto barriga, cabeça, facão e cotovelo são elementos acessórios/especificativos. Vale salientar que, assim como acontece com as bases nas construções sufixadas, esse elemento não núcleo participa ativamente da construção do significado da palavra instanciada pelo esquema. Em dor de facão, por exemplo, o significado não pode ser analisado como uma dor tópica como em dor de cabeça e dor de barriga. A expressão dor de facão, muito comum em algumas regiões do Brasil, se refere a uma "dor pontiaguda e forte situada no lado direito do abdome, altura do baço” (LINS, 2014). O elemento facão, então, é tomado metaforicamente, por uma relação de semelhança. Cabe observar que, na LC, o significado metafórico, resultante de um mapeamento por meio de semelhança, é construído no sistema conceptual do falante, podendo, em muitos casos, não ser uma relação que se verifica no mundo real. No caso de dor de facão, o falante mapeia a sensação da dor com a sensação da penetração de um facão no baço.

No Quadro 4, foram selecionadas dez composições com sindrome/complexo, para serem comentadas quanto à participação do elemento não núcleo na formação de sentido. A análise se orienta tanto pelo modus operandi de Soledade (2018a), uma vez que se destacam os aspectos metafóricos e metonímicos desses elementos, quanto pelas noções de 'sistema conceptual' (LAKOFF; JOHNSON, 2002 [1980]) e de 'modelo cognitivo idealizado' (LAKOFF, 1987).

\begin{tabular}{l|c|c} 
Construções & Contextos & Comentários \\
\hline Síndrome de índio & $\begin{array}{c}\text { Dormi de casaco, calça e meia. Acordei sem nada! N } \\
\text { sei q sindrome de indio é essa q eu tenho q n consigo } \\
\text { dormir de roupa" (ABRRT, 2017). }\end{array}$ & $\begin{array}{c}\text { Nessa construção, trabalha-se com um } \\
\text { modelo cognitivo idealizado de indio, } \\
\text { bastante ligado aos povos originários. A } \\
\text { partir desse modelo, seleciona-se o aspecto } \\
\text { da nudez na construção. O elemento indio, } \\
\text { portanto, é tomado metonimicamente. }\end{array}$ \\
\hline Síndrome de Sol & $\begin{array}{c}\text { "Esse povo com sindrome de Sol juram que tudo que a a } \\
\text { gente faz gira em torno dela" (GIFS DA VIDA REAL, } \\
\text { 2017). }\end{array}$ & $\begin{array}{c}\text { O Sol é tomado metonimicamente por sua } \\
\text { centralidade no sistema solar, em que todos } \\
\text { os planetas giram em torno dele. Nesse caso, } \\
\text { há uma metaforizaça também nas relações } \\
\text { humanas: uma pessoa que se assemelha ao } \\
\text { Sol, protagonista, e outras que seriam os } \\
\text { planetas, coadjuvantes. }\end{array}$ \\
\hline Síndrome de mendigo & $\begin{array}{c}\text { Eu tenho algum tipo de síndrome de mendigo que me } \\
\text { puxa pra sentar/deitar em qualquer lugar, no chão" } \\
\text { (ALECRIM, 2017). }\end{array}$ & $\begin{array}{c}\text { Trabalha-se aqui com um modelo cognitivo } \\
\text { idealizado de mendigo, acreditando que esse } \\
\text { dorme em qualquer lugar. Nesse caso, o } \\
\text { elemento mendigo é tomado } \\
\text { metonimicamente. }\end{array}$ \\
\hline
\end{tabular}


"Gente assim deve ter 'sindrome d cirurgião': quer meter a mão nas partes internas interiores dos recônditos + profundos da condição humana" (MADUREIRA, 2017).
No contexto em questão, os falantes falavam da prática sexual fist-fucking, em que uma pessoa insere a mão ou o punho no ânus ou na vagina da outra. A prática é conceptualizada como uma cirurgia, e a pessoa praticante ativa (aquela que penetra a mão ou punho) é tomada metaforicamente como o cirurgião.

O antibiótico é aqui tomado

"Conversar com pessoas que tem síndrome de antibiótico te responde de $8 \mathrm{em} 8$ horas" (TALIRA, 2017).

metonimicamente, pelo fato de muitos remédios dessa especificidade serem usados de 8 em 8 horas.

O termo underground é utilizado para se referir a um movimento que atua fora do comum, com ideias vanguardistas e heterodoxas. No contexto apresentado, a palavra underground é tomada metonimicamente pelo seu aspecto prático.

O antropônimo João Dória Jr., atual prefeito da cidade de São Paulo, é tomado metonimicamente pelas suas medidas de pintar de cinza os muros pintados e grafitados por artistas de rua da cidade.

Outro antropônimo tomado metonimicamente, remetendo à situação em que $o$ apresentador Luciano Huck apagou as suas fotos com o seu amigo, $\mathrm{O}$ senador Aécio Neves, após este ser denunciado em um escândalo de corrupção.

Cinderela é tomada metonimicamente nessa construção, em função da sua história, contada em livros infantis. O que se transporta para a construção é o fato de Cinderela ter ficado rica por um passe de mágica.

A construção remonta à personagem Wendy, da história de Peter Pan. É uma personagem que se preocupa

"Se aquela fdp tivesse o complexo de wendy talvez Complexo de Wendy soubesse o quão frustrante é querer ser responsável o tempo todo por tudo" (RAFAELA, 2017). excessivamente com o protagonista e com os demais. Por isso, o complexo de Wendy caracteriza um comportamento em que a pessoa assume a responsabilidade por tudo e por todos. Significado metonímico.

Quadro 4: Análise dos elementos não núcleos nos compostos síndrome/complexo

Fonte: Produzido pelo autor

A partir dos exemplos do Quadro 4, pode-se dizer que a metonímia se mostra mais produtiva na herança semântica dos elementos não núcleos nos compostos. Nos compostos com complexo, há, na maioria dos casos, uma metonímia de algum aspecto da vida de personagens míticos ou literários, como Cinderela e Wendy. Exemplos não vistos no Quadro 4 que seguem essa tendência são os complexos de Édipo, Electra, Jocasta.

Em relação aos compostos com síndrome, os exemplos do Quadro 4 são, em grande maioria, metonímicos, pois apontam para aspectos de focalização e seleção de conhecimento acerca de eventos e entidades, como o Sol, o índio, Luciano Huck, João Dória Jr. 
Para além dos exemplos do Quadro 4, nota-se, do ponto de vista da herança, que há uma tendência metonímica do tipo CIENTISTA/DESCOBERTA em muitos constructos, como Sindrome de Waardenburg, Sindrome de Asperger e Sindrome de Brugada. Esses costumam acontecer, sobretudo, como subesquemas de condições clínicas.

\section{CONSIDERAÇÕES FINAIS}

Neste trabalho, foram analisados compostos do português brasileiro encabeçados pelas palavras síndrome e complexo, com base nos pressupostos teóricos da Morfologia Construcional, como trabalhada por Booij (2010) e Gonçalves (2016). Apesar de o estudo da composição morfossintática ainda ser pouco frequente nesse modelo teórico, os resultados aqui apresentados mostram que esses compostos podem ser esquematizados com o mesmo êxito e elegância de outros processos formativos recorrentemente abordados, como a sufixação e a prefixação.

Quanto às análises propriamente ditas, verificou-se que os compostos sindrome são mais produtivos que os complexo. Os compostos síndrome são dominados pela noção de anomalia, seja como uma condição clínica (síndrome de Asperger, síndrome de Down, síndrome de Waardenburg etc.), seja como um comportamento anormal (síndrome de trouxa, síndrome do pau pequeno, síndrome de cirurgião etc.). Os compostos complexo, por outro lado, não apresentam um esquema dominante especificado, visto que, junto com os significados de condição psicológica (complexo de inferioridade, complexo de Édipo, complexo de Messias) e de comportamento anormal (complexo de Cinderela, complexo de Wendy, complexo de Deus), encontra-se uma noção coletiva (complexo do Alemão, complexo de Bangu, complexo do Lins), que destoa relativamente dos outros significados. Em termos de aproximação, o significado comportamento anormal, verificado tanto nos compostos sindrome quanto nos compostos complexo, tem viabilizado o aparecimento de formas duplas, como complexo/síndrome de Dona Florinda, complexo/síndrome de vira-lata e complexo/sindrome de Deus.

O artigo discutiu ainda a questão da herança semântica da base, feita por alguns poucos autores no âmbito da derivação, mas observável também nos compostos, em relação à herança semântica dos elementos variáveis não núcleos. As análises empreendidas quanto a esse fenômeno apenas ratificaram as observações de Booij (2010) e Gonçalves (2016) de que compostos, derivados prefixais e derivados sufixais apresentam mais semelhanças que diferenças na esquematização. Os resultados vistos entre os compostos encontram total correspondência com o que se verifica nos derivados.

\section{REFERÊNCIAS}

ABRRT, C. Dormi de casaco, calça e meia. Acordei sem nada! N sei q síndrome de índio é essa q eu tenho q $\mathrm{n}$ consigo dormir de roupa. Brasil (26 ago. 2017). Twitter: @carlaabrrt. Disponível em: https://twitter.com/Carlaabrrt/status/901405040291852292 . Acesso em: 25 set. 2017.

ALECRIM, V. Eu tenho algum tipo de síndrome de mendigo que me puxa pra sentar/deitar em qualquer lugar, no chão. Brasil (6 set. 2017). Twitter: @victoralecrim. Disponível em: https://twitter.com/victoralecrim/status/905466027131232256. Acesso em: 25 de setembro de 2017.

ARONOFF, M. Word formation in generative grammar. Cambridge: MIT Press, 1976.

AULETE, C. iDicionário Aulete. Disponível em: http://www.aulete.com.br. Acesso em: 11 jan. 2019.

BARROS, C. Quem Sérgio Moro pensa que é pra não cumprir a ordem do TRF4 de soltar Lula? Essa síndrome de Deus dele já foi longe demais. Brasil (8 jul. 2018). Twitter: @calu_barros. Disponível em: https://twitter.com/calu_barros/status/1015991613611536384. Acesso em: 11 jan. 2019. 
BASÍLIO, M. Estruturas lexicais do português: uma abordagem gerativa. Petrópolis: Vozes, 1980.

BAUER, L. English word-formation. Cambridge: Cambridge University Press, 1983.

BOOIJ, G. Compounding and derivation: evidence for construction Morphology. In: DRESSLER, W. et al. (Ed.). Morphology and its demarcations. Amsterdam: John Benjamins Publishing Company, 2005. p. 109-131.

Construction Morphology. Oxford: Oxford University Press, 2010.

. Form and meaning in morphology: the case of Dutch 'agent nouns'. Linguistics, Berlin, n. 24, p. 503-517, 1986.

. Inheritance and motivation in Construction Morphology. In: GISBORNE, Nikolas; HIPPISLEY, Andrew (Ed.). Defaults

in morphological theory. Oxford: Oxford University Press, 2017. p. 18-39. Disponível em: $<$ https://geertbooij.files.wordpress.com/2014/02/booij-2015-inheritance-issues-in-constructionmorphology-feb-2014.pdf > Acesso em: 22 set. 2017.

CASTILHO, R. O Reaça Pobre e a Síndrome de Dona Florinda. 2014 . Disponível em: http://blogdorafaelcastilho.blogspot.com/2014/09/o-reaca-pobre-e-sindrome-de-dona.html. Acesso em: 23 set. 2017.

CONSELHO DE NOIA. Tem gente que vem de rabo abanando quando termina o namoro, diz que agora já era, aí ataca a síndrome de trouxa volta com o/a ex . São Paulo, Brasil (28 ago. 2017). Twitter: @conselhodenoia. Disponível em: https://twitter.com/ironicomkofc/status/902167660401713152. Acesso em: 25 set. 2017.

CORBIN, D. Associativité et stratification dans la représentation des mots construits. In: DRESSLER, W.U et al. Contemporary morphology. New York: Mouton de Gruyter, 1990. p. 43-59.

CUNHA, A. G. Dicionário etimológico da língua portuguesa. 3. ed. Rio de Janeiro: Lexikon, 2007.

DIÁRIO DO CENTRO DO MUNDO. Síndrome de Luciano Huck. Gabeira apaga fotos com os amigos do MBL. Brasil (13 set. 2017). Twitter: @DCM_Online. Disponível em: https://twitter.com/DCM online/status/907920514726944768. Acesso em: 25 set. 2017.

DOBRORUKA, V. Considerações sobre o pensamento trinitário de Joaquim de Fiore em suas relações com as filosofias especulativas da história. Revista Múltipla, Brasília, v. 6, n.8, p. 9-27, 2000.

FARIA, A. L. Motivação morfossemântica das construções compostas N-N no português brasileiro. 2011. 189 f. Tese (Doutorado em Língua Portuguesa) - Faculdade de Letras, Universidade Federal do Rio de Janeiro, Rio de Janeiro, 2011.

FERNANDES, P. R. PTB aparelhou a Casa da Moeda, agora está com síndrome de Tio Patinhas, não quer a privatização!. Brasil (26 ago. 2017). Twitter: @mpaularfer. Disponível em: https://twitter.com/mpaularfer/status/901463045913927681. Acesso em 25 set. 2017.

GIFS DA VIDA REAL. Esse povo com síndrome de Sol juram que tudo que a gente faz gira em torno dela. Brasil (5 set. 2017). Twitter: @gifsvidareal. Disponível em: https://twitter.com/gifsvidareal/status/905112344346447877. Acesso em: 25 set. 2017.

GIO. Adolescente com síndrome de underground q acha q as series/filmes/bandas são exclusivas vcs precisam de acompanhamento psiquiátrico e eu falo seríssimo. Brasil (11 jan. 2019). Twitter: @desgrazinha. Disponível em: https://twitter.com/desgrazinha/status/1083751417242943488. Acesso em: 11 jan. 2019. 
GOLDBERG, A. E. Constructions: a construction grammar approach to argument structure. Chicago: University of Chicago Press, 1995.

Constructions at work: the nature of generalization in language. Oxford: Oxford University Press, 2006.

GONÇALVES, C. A. V. Flexão e derivação: o grau. In: VIEIRA, S. R.; BRANDÃO, S. F. Ensino de gramática: descrição e uso. 2. ed. São Paulo: Contexto, 2013. p. 147-167.

. Morfologia construcional: uma introdução. São Paulo: Contexto, 2016.

GONÇALVES, C. A. V.; ALMEIDA, M. L. L. de. Morfologia Construcional: o que é e como se faz. In: GONÇALVES, C. A. V. Morfologia construcional: uma introdução. São Paulo: Contexto, 2016. p. 11-48.

HOUAISS, A.; VILLAR, M. Dicionário eletrônico Houaiss da Língua Portuguesa. Rio de Janeiro: Objetiva, 2009. CD-ROM.

JACKENDOFF, R. Morphological and semantic regularities in the lexicon. Language, v. 51, n. 3, p. 639-671, 1975.

JAN, L. M. Meu pai tô com síndrome de virginiano só reglama de limpeza aaaaaaaa. Brasil (26 ago. 2017). Twitter: @jungleyoungjan. Disponível em: https://twitter.com/jungleyoungjan/status/901493411617832960. Acesso em: 25 set. 2017.

JOREIVAX. Para os coxinhas que tem complexo de cinderela a se realizar no 'american dream', esse é o braZil perfeito. Brasil (8 set. 2017). Twitter: @Jollimaa. Disponível em: https://twitter.com/Jollimaa/status/906316574570762240. Acesso em: 25 set. 2017.

KILEY, D. The Peter Pan Syndrome: men who have never grown up. New York: Dodd Mead, 1983.

KINGCOCK, J. Já repararam como eu me odeio e tenho complexo de Deus? É muito engraçado e explicável cientificamente. Brasil (24 set. 2017). Twitter: @ jesusvckingcock. Disponível em: https://witter.com/jesusvckingcock/status/911930465808011264. Acesso em: 25 set. 2017.

LAKOFF, G. Women, fire, and dangerous things. Chicago, IL: Chicago University Press, 1987.

LAKOFF, G.; JOHNSON, M. Metáforas da vida cotidiana. Coordenação de tradução: Mara Sophia Zanotto. Campinas: Mercado das Letras; São Paulo: Educ, 2002. [1980].

LINS, C. Dor de facão. Dicionário Informal. Disponível em: https://www.dicionarioinformal.com.br/dor+de+fac\%E3o/. Acesso em: 11 jan. 2019.

MADUREIRA, F. Gente assim deve ter 'síndrome d cirurgião': quer meter a mão nas partes internas interiores dos recônditos + profundos da condição humana. Brasil (29 ago. 2017). Twitter: @FabioMadureira. Disponível em: https://twitter.com/FabioMadureira/status/902569661924966405. Acesso em: 25 set. 2017.

MARINATO, P. Eu me engano mt com as pessoas, tenho a síndrome da bela e a fera, fico tentando achar qualidades em quem na vdd é só um monstro msm. Brasil (3 nov. 2017). Twitter: @Pri_Marinato. Disponível em: https://twitter.com/Pri Marinato/status/926636373515427845. Acesso em: 11 jan. 2019. 
MBRANDREA. Exato! Renato Sabia das coisas, não tinha complexo de Peter pan nem queria ser forever Young . Brasil (24 set. 2017). Twitter: @MBRAndrea. Disponível em: https://twitter.com/MBRAndrea/status/912106965211508736. Acesso em: 25 set. 2017.

MELO, C. N. de. Sobre coleções e lugares: o caso das formações X-teca do português brasileiro. 2017. 86 f. Dissertação (Mestrado em Língua Portuguesa) - Faculdade de Letras, Universidade Federal do Rio de Janeiro, Rio de Janeiro, 2017.

MIRANDA, F. Síndrome de vira-lata: precisamos falar sobre isso. 2017. Disponível em: https://www.brasil247.com/pt/colunistas/fatimamiranda/298587/\%E2\%80\%9CS\%C3\%ADndrome-de-vira-lata\%E2\%80\%9Dprecisamos-falar-sobre-isso.htm. Acesso em: 23 set. 2017.

NALUY, M. Por aqui nada cinza, só cultura e arte. Que a Síndrome João Dória Jr não nos alcance jamais. Brasil (8 set. 2017). Twitter: @MaisaNaluy. Disponível em: < https://twitter.com/MaisaNaluy/status/906312863408672768 >. Acesso em: 25 de setembro de 2017

RAFAELA. Se aquela fdp tivesse o complexo de wendy talvez soubesse o quão frustrante é querer ser responsável o tempo todo por tudo. Brasil (12 mar. 2017). Twitter: @kindkurama. Disponível em: https://twitter.com/kindkurama/status/840806725989126145. Acesso em: 25 set.2017.

ROSSATTO, N. D.; COSTA, M. R. N; TER REGEEN, J. Ação, escolha e justiça: Joaquim de Fiore e a inversão de Trasímaco. Anais do XI Congresso Latino-Americano de Filosofia Medieval. Fortaleza-CE: Universidade Estatual Fortaleza, 2006. v. 1. p. 1-11.

SAH. Ariana com síndrome do Peter Pan. Pqp eu tô rindo muito. Brasil (30 ago. 2017). Twitter: @moonIighr. Disponível em: https://twitter.com/moonIighr/status/902993340056178693. Acesso em: 25 set. 2017.

SILVA, J. C. T. da. Esquemas de imagem na formação de denominais em português: o caso de -eiro e -ário. 2017.226 f. Tese (Doutorado em Língua Portuguesa) - Faculdade de Letras, Universidade Federal do Rio de Janeiro, Rio de Janeiro, 2017.

SILVA, N. H. da. Metáfora e metonímia nas construções com 'pé’: uma abordagem cognitivista. 2011. 112 f. Dissertação (Mestrado em Língua Portuguesa) - Faculdade de Letras, Universidade Federal do Rio de Janeiro, Rio de Janeiro, 2011.

SIMÕES NETO, N. A. Morfologia Construcional e alguns desafios para a análise de dados históricos da língua portuguesa. Domínios de Lingu@gem, Uberlândia, v. 11, n.3, p. 468-501, 2017.

Um enfoque construcional sobre as formações X-eir-: da origem latina ao português arcaico. 2016. 655 f. Dissertação (Mestrado em Língua e Cultura) - Instituto de Letras, Universidade Federal da Bahia, Salvador, 2016. 2 tomos.

SIQUEIRA, A. O Complexo de Dona Florinda. 2014. Disponível em: http://brasilemdiscussao.blogspot.com/2014/09/criei-essetermo-eu-pensava-muito.html. Acesso em: 23 set. 2017.

SMITH, A. Blogueiro britânico diz que brasileiros exageram na rejeição ao Brasil. 2015. Disponível em: https://www.bbc.com/portuguese/noticias/2015/05/150428 parainglesver adamsmith2 ss. Acesso em: 23 set. 2017. 
SOLEDADE, J. De pecadores a sabedores: agentes de -dor no Livro das Aves. In: ALMEIDA, A. A. D.; LOPES, M. S. Livro em homenagem aos 50 anos da edição do Livro das Aves. 2018a. [No prelo].

. Experimentando esquemas: um olhar sobre a polissemia das formações [[X - EIR]N] no português arcaico. Revista Diadorim / Revista de Estudos Linguísticos e Literários, Rio de Janeiro, número especial, p. 83-111, 2013.

. Por uma abordagem cognitiva da morfologia: revisando a morfologia construcional. In: ALMEIDA, A. A. D.; SANTANA, E. S. (Orgs.). Linguística Cognitiva: redes de conhecimento d'aquém e d'além mar Salvador: Edufba, 2018b, p. 345-378.

TALIRA. Conversar com pessoas que tem síndrome de antibiótico te responde de 8 em 8 horas. Brasil (29 ago. 2017). Twitter: @atilsat. Disponível em: < https://twitter.com/atilsat/status/902563088465059844>. Acesso em: 25 set. 2017.

VILLALVA, Alina. Formação de palavras: composição. In: MATEUS, M. H. M. et al.. Gramática da Língua Portuguesa. 7. ed. Lisboa: Caminho, 2003. p. 969-983.

\section{(ㄷ) (1) $\circledast \circledast$}

